\title{
Vaccine completion and infectious diseases screening in a cohort of adult refugees following resettlement in the U.S.: 2013- 2015
}

Amir M. Mohareb ${ }^{1,2,3^{*}}$, Bryan Brown ${ }^{4}$, Kevin S. Ikuta ${ }^{5,6}$, Emily P. Hyle ${ }^{1,2,3}$ and Aniyizhai Annamalai ${ }^{4,7}$

\begin{abstract}
Background: Refugees are frequently not immune to vaccine-preventable infections. Adherence to consensus guidelines on vaccination and infectious diseases screening among refugees resettling in the U.S. is unknown. We sought to determine rates of vaccine completion and infectious diseases screening in refugees following resettlement.

Methods: We conducted a retrospective cohort study of refugees resettling in a region in the U.S. using medical data from June 2013-April 2015. We determined the proportion of vaccine-eligible refugees vaccinated with measlesmumps-rubella (MMR), hepatitis A/B, tetanus, diphtheria, and acellular pertussis (Tdap), and human papillomavirus (HPV) following resettlement. We also determined the proportion of refugees who completed HIV and hepatitis $C$ (HCV) screening.

Results: One hundred and eleven subjects were included, primarily from Iraq (53\%), Afghanistan (19\%), and Eritrea (11\%). Of the 84 subjects who were vaccine-eligible, 78 (93\%) initiated and 42 (50\%) completed vaccinations within one year of resettlement. Odds of completing vaccination were higher for men (OR: 2.38; 95\%Cl:1.02-5.71) and for subjects with English proficiency (OR: 3.70; 95\%Cl:1.04-17.49). Of the 78 subjects (70\%) completing HIV screening, two (3\%) were diagnosed with HIV. Nearly all subjects completed screening for HCV, and one had active infection.

Conclusion: While most refugees initiate vaccinations, only 50\% completed vaccinations and 70\% completed HIV screening within 1 year of resettlement. There is a need to emphasize vaccine completion and HIV screening in refugee patients following resettlement.
\end{abstract}

Keywords: Refugees, Hepatitis B, Hepatitis C, HIV, MMR, HPV, Immunizations

\section{Background}

There has been an unprecedented rise in vaccinepreventable infections around the world, including in immigrant and refugee communities [1,2]. The number of refugees being resettled in the U.S. was severely

\footnotetext{
* Correspondence: amohareb@mgh.harvard.edu

${ }^{1}$ Medical Practice Evaluation Center, Massachusetts General Hospital, 16th Floor, 100 Cambridge Street, Boston, MA 02114, USA

${ }^{2}$ Division of Infectious Diseases, Massachusetts General Hospital, Boston, MA, USA

Full list of author information is available at the end of the article
}

limited between 2017 and 2020, but it is expected to rise in the coming years due to anticipated changes in federal policy on refugee resettlement. Unlike most immigrant groups in the U.S., U.S.-bound refugees are not required to receive vaccinations prior to arrival [3]. Prior studies in refugees have demonstrated low rates of baseline immunity to vaccine-preventable infections, including measles, mumps, rubella (MMR), and viral hepatitis [4-9]. To address this, the U.S. Centers for Disease Control and Prevention (CDC) and the U.S. Department of State

(C) The Author(s). 2021 Open Access This article is licensed under a Creative Commons Attribution 4.0 International License, which permits use, sharing, adaptation, distribution and reproduction in any medium or format, as long as you give appropriate credit to the original author(s) and the source, provide a link to the Creative Commons licence, and indicate if changes were made. The images or other third party material in this article are included in the article's Creative Commons licence, unless indicated otherwise in a credit line to the material. If material is not included in the article's Creative Commons licence and your intended use is not permitted by statutory regulation or exceeds the permitted use, you will need to obtain permission directly from the copyright holder. To view a copy of this licence, visit http://creativecommons.org/licenses/by/4.0/ The Creative Commons Public Domain Dedication waiver (http://creativecommons.org/publicdomain/zero/1.0/) applies to the data made available in this article, unless otherwise stated in a credit line to the data. 
developed a pre-departure vaccination program for U.S.bound refugees, which has been growing in implementation since 2013 [10]. However, gaps in immunity may still persist, particularly in refugees resettled prior to or in the early years of this program. Although guidance from the $\mathrm{CDC}$ recommends vaccinating eligible refugees following resettlement [3], the proportion of refugees who complete post-resettlement vaccination, especially of multidose vaccines, is unknown.

Screening practices for HIV and hepatitis $\mathrm{C}$ virus (HCV) among refugees in the post-resettlement period are also unknown. Mandatory pre-departure HIV screening has not been conducted in U.S.-bound refugees since 2010 $[11,12]$. Therefore, HIV screening is recommended for all refugees following resettlement [12], but these recommendations may not be consistently followed [13, 14]. Our objective was to determine the proportion of refugees who complete post-resettlement vaccination and HIV and HCV screening.

\section{Methods \\ Population}

We conducted a retrospective cohort study of adult refugees resettling in a district in Connecticut, U.S. All refugees resettling in this region underwent screening in a dedicated clinic and continued to receive follow-up care in the same primary care network. We considered adult refugees (age at least 18 years-old at the time of resettlement) eligible for inclusion if they had 1 year of followup clinical data after completing a medical screening exam, which included serologic testing of immunity by immunoglobulin G (IgG) for measles, mumps, rubella (MMR), hepatitis A, hepatitis B, and varicella. Immunity testing for tetanus, diphtheria, or pertussis (Tdap) was not available. We considered subjects eligible for one of these vaccines if they did not have a positive IgG or evidence of overseas documentation of vaccination. We considered all males and females 26 years-old and younger to be eligible for three doses of the human papillomavirus (HPV) vaccine $[15,16]$. We ascertained the proportion of eligible refugees who initiated HPV vaccine series because none were previously vaccinated prior to resettlement. We also determined the proportion of refugees who completed screening for HIV by a fourth generation antibody-antigen test and HCV by IgG antibody testing.

\section{Data collection}

We collected data from the medical record on subjects' age, sex, country of origin, and English proficiency, defined as not requiring a medical interpreter during clinical visits. We defined country of origin as the country of primary residence immediately prior to resettlement. We captured vaccinations and $\mathrm{HIV} / \mathrm{HCV}$ screening information from the time of initial evaluation until 1 year following resettlement for each subject. We used this timeframe because it encompasses the period during which federal health insurance (i.e., Refugee Medicaid Assistance) is available in the U.S. for this patient population [17]; therefore, refugees in this cohort should have no lapses in health insurance coverage during the study, which might otherwise affect vaccine completion. We included all refugees who resettled in this region from June 1, 2013, to April 30, 2014, and collected data through April 30, 2015. All subjects were confirmed to remain in the same primary care network for 1 year following resettlement. These dates of inclusion were chosen because after April 2014, refugees newly resettling in this region were not consistently retained in the same primary care network, so follow-up vaccine completion would not be reliably ascertained.

\section{Statistical analysis}

We analyzed the proportion of subjects who were immune and the proportion of vaccine-eligible subjects who initiated and completed MMR, hepatitis A/B, Tdap, and HPV vaccinations within 1 year after resettlement. Varicella vaccine was not readily available for administration in the clinic, so we reported baseline varicella immunity only. We also analyzed MMR and hepatitis A/B in aggregate by the following definition: those nonimmune to any of these diseases were considered nonimmune to the aggregate and were vaccine-eligible; among those who were vaccine-eligible, only those completing all necessary vaccines so that they were fully immune were considered successfully vaccinated. We evaluated predictors of complete vaccination at 1 year post-resettlement among those who were vaccineeligible by univariable analysis. We defined statistical significance as two-tailed $p<0.05$, and we used $\mathrm{R}$ version 3.5.1 for statistical computation. The sample size of this cohort did not allow for a stable multivariable analysis of our characteristics of interest: age, sex, country of origin, and English language proficiency. This study was approved by the institutional review boards of participating institutions.

\section{Results}

A total of 111 subjects met inclusion criteria for this study (Table 1). The mean age was 34 years (range: 1976 years), and $41 \%$ were female. Countries of origin included Iraq (53\%), Afghanistan (19\%), Eritrea (11\%), and Ethiopia (5\%); the remainder (13\%) were from other countries of origin (i.e., Sudan, Syria, the Democratic Republic of Congo, and Colombia). The median time between resettlement in the U.S. and initial assessment in the refugee clinic was 34 days (interquartile range: 1544 days). 
Table 1 Baseline Characteristics of Adult Refugees Resettling in a Connecticut district, 2013-2015

\begin{tabular}{ll}
\hline Variable & Value \\
\hline Total participants, $\mathrm{n}$ & 111 \\
Age, median (IQR), years & $30(18-76)$ \\
Sex, $\mathrm{n}(\%)$ female & $45(41 \%)$ \\
Country of Origin, $\mathrm{n}(\%)$ & \\
$\quad$ Iraq & $59(53 \%)$ \\
$\quad$ Afghanistan & $20(19 \%)$ \\
$\quad$ Eritrea & $12(11 \%)$ \\
$\quad$ Ethiopia & $6(5 \%)$ \\
$\quad$ Other & \\
Time between resettlement and screening, & $14(13 \%)$ \\
median (IQR), days & $34(15-44)$ \\
$\begin{array}{l}\text { English proficiency, } \mathrm{n}(\%) \\
\text { Resettled simultaneously with family } \\
(>1 \text { person), number (\%) }\end{array}$ & $20(18 \%)$ \\
\hline $\begin{array}{l}\text { Note: IQR Interquartile range } \\
\text { a Other countries include Sudan, Syria, the Democratic Republic of Congo, } \\
\text { and Colombia }\end{array}$ & $85(77 \%)$ \\
\end{tabular}

Aggregate baseline immunity to all of measles, mumps, rubella, hepatitis A, and hepatitis B was present in 27 (24\%) subjects (Table 2). Of the remaining 84 subjects who were vaccine-eligible for $\mathrm{MMR}$, hepatitis $\mathrm{A}$, or hepatitis B, 42 (50\%) were fully vaccinated within 1 year of resettlement date. Serologic immunity and vaccine completion varied by country of origin (Fig. 1). Twentyeight subjects $(25 \%)$ were non-immune to any of measles, mumps, or rubella. Of these 28 subjects, 20 (71\%) completed the two-dose MMR vaccine series, 6 (21\%) received one dose of the series, and $2(8 \%)$ did not initiate the series within 1 year of resettlement. Seventyeight subjects (70\%) were non-immune to hepatitis B. Of these, 46 (59\%) completed the three-dose vaccine series within 1 year, 26 (33\%) had initiated but not completed the series, and $6(8 \%)$ did not initiate the series within 1 year of resettlement. Nearly all subjects (96\%) were vaccinated with Tdap after resettlement. Baseline immunity to varicella was present in $90 \%$ of subjects. Thirty-four subjects met criteria for the HPV vaccine series (i.e., age below 26 years), of whom 5 (15\%) received at least one dose during the study period.

Among those who were vaccine-eligible, older age was associated with a lower odds of vaccine completion (for each year increase in age, OR: 0.96, 95\%CI: 0.93-0.99). In particular, subjects older than 50 years-old had a much lower odds of vaccine completion compared to those younger than 50 years-old (OR 0.12, 95\%CI: $0.02-$ $0.47)$. A higher odds of vaccine completion was noted in subjects who were male (OR: 2.38, 95\%CI: 1.02-5.71) and English speakers (OR: 3.70, 95\%CI: 1.04-17.49). Country of origin was not associated with a difference in vaccine completion (Table 3 ).

Of the 78 subjects (70\% of the cohort) completing HIV screening, two (3\%) were diagnosed with HIV after confirmation with HIV RNA testing. Both were successfully linked to care at a local HIV clinic. One hundred and ten subjects (99\% of the entire cohort) completed screening for $\mathrm{HCV}$; two subjects (2\%) were positive for $\mathrm{HCV} \mathrm{Ab}$, of whom one had detectable HCV RNA.

\section{Discussion}

Among 111 resettled refugees, 84 (76\%) were eligible for at least one of the following vaccines: MMR, hepatitis A, or hepatitis B. Although $93 \%$ of vaccine-eligible subjects initiated vaccination(s), only $50 \%$ completed vaccinations within 1 year of resettlement. This demonstrates that refugees who resettled in the U.S. during this time period (2013-2014) remain vulnerable to vaccinepreventable infections long after resettlement.

Table 2 Baseline Vaccine-Eligibility, Initiation, and Completion of Recommended Vaccinations Among Adult Refugees in a Connecticut district, 2013-2015

\begin{tabular}{|c|c|c|c|c|}
\hline \multirow[b]{2}{*}{ Vaccine } & \multicolumn{2}{|c|}{$\begin{array}{l}\text { Baseline Immunity Among All } 111 \text { Subjects at the Time of } \\
\text { Resettlement } \\
\mathrm{n}(\%)\end{array}$} & \multicolumn{2}{|c|}{$\begin{array}{l}\text { Vaccinations One Year after Resettlement Among } \\
\text { Vaccine-Eligible Subjects } \\
\text { n (\%) }\end{array}$} \\
\hline & Immune & Non-immune (Vaccine-Eligible) & Initiated & Completed \\
\hline Aggregate $^{a}$ & $27(24 \%)$ & 84 (76\%) & 78 (93\%) & 42 (50\%) \\
\hline MMR (2 doses) & $83(75 \%)$ & $28(25 \%)$ & $26(93 \%)$ & $20(71 \%)$ \\
\hline Hep A (2 doses) & $93(84 \%)$ & $18(16 \%)$ & $16(89 \%)$ & $15(83 \%)$ \\
\hline Hep B (3 doses) & $33(30 \%)$ & $78(70 \%)$ & $72(92 \%)$ & $46(59 \%)$ \\
\hline Tdap (1 dose) & N/A & 111 (100\%) & 106 (96\%) & 106 (96\%) \\
\hline HPV $(3 \text { doses })^{b}$ & $\mathrm{~N} / \mathrm{A}$ & $34(31 \%)$ & $5(15 \%)$ & $1(20 \%)$ \\
\hline Varicella & 100 (90\%) & $11(10 \%)$ & N/A & N/A \\
\hline
\end{tabular}

Note: MMR Measles, mumps, rubella, Hep A Hepatitis A, Hep B Hepatitis B, Tdap Tentanus, diphtheria, acellular pertussis, HPV Human papillomavirus. Baseline immunity determined by laboratory testing for immunoglobulin $\mathrm{G}$ or documentation of completed overseas vaccination

${ }^{a}$ Aggregate of measles, mumps, rubella, hepatitis $A / B$; we considered subjects to be vaccine-eligible if they required any of these vaccines

${ }^{b} \mathrm{HPV}$ vaccine eligibility was assumed for all subjects $<26$ years-old. No subject had documentation of prior HPV vaccination 


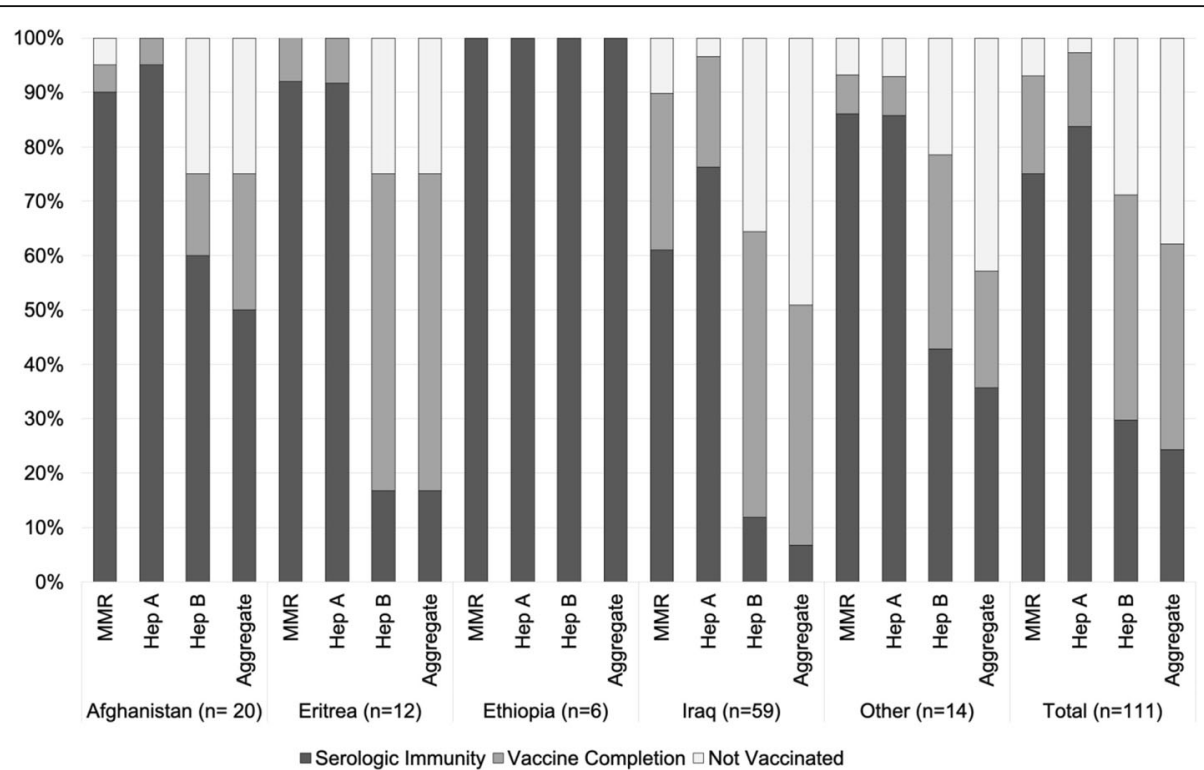

Fig. 1 Serologic immunity and vaccine completion for multi-dose vaccine series up to one year after resettlement in a cohort of refugees in Connecticut, 2013-2015. Note: MMR = measles, mumps, rubella; Hep A = hepatitis A; Hep B= hepatitis B

A plausible reason for incomplete immunization is patient acceptability to return to clinic for multi-dose vaccine series. This may be why the three-dose series for hepatitis B had a lower completion rate (59\%) than hepatitis A (83\%) or MMR (71\%), both of which are two-dose series, and Tdap (96\%), a one-dose series. One

Table 3 Factors Associated with Vaccine Completion Among Adult Refugees in a Connecticut district, 2013-2015

\begin{tabular}{ll}
\hline Age (per year) & $\begin{array}{l}\text { Odds Ratio }(\mathbf{9 5} \% \mathrm{Cl}) \text { of Vaccine } \\
\text { Completion }^{\mathbf{a}}(\boldsymbol{n}=\mathbf{8 4})\end{array}$ \\
Age (binary) & $0.96(0.93-0.99)^{*}$ \\
Age $<50$ & Reference \\
Age $\geq 50$ & $0.12(0.02-0.47)^{*}$ \\
Sex & \\
Female & Reference \\
Male & $2.38(1.02-5.71)^{*}$ \\
English proficiency & \\
No & Reference \\
Yes & $3.70(1.04-17.49)^{*}$ \\
Country of Origin & \\
Iraq & Reference \\
Afghanistan & $0.42(0.12-1.25)$ \\
Eritrea & $2.54(0.72-10.38)$ \\
Ethiopia & $0.25(0.01-1.70)$ \\
Other & $0.95(0.28-3.08)$
\end{tabular}

${ }^{a}$ Tdap, MMR, hepatitis A/B

${ }^{\mathrm{b}}$ Comprised of Sudan, Syria, the Democratic Republic of Congo, and Colombia $* p<0.05$ factor that may improve these rates in the U.S. is implementation of the CDC Overseas Vaccination Program for U.S.-bound Refugees, a program which initiates ageappropriate vaccinations at international asylum sites in the months prior to departure to the U.S. At the time of our study, this program was beginning to be implemented in six countries but has since expanded to all sites processing U.S.-bound refugees. Documentation of overseas vaccinations at these sites is available to health providers in the U.S. through the CDC Electronic Disease Notification system [18].

The refugee health assessment is an important opportunity to ensure MMR immunity among refugee patients [1]. In this cohort, one in four subjects required MMR vaccination after resettlement. A prior study found a lower rate of MMR-eligible refugees (10\%) from a sampling of asylum countries in East Africa and Southeast Asia [5]. That study found that $4 \%$ of MMR-eligible refugees did not receive a dose of the MMR vaccine during their initial encounter for the refugee health assessment, but they were unable to determine if vaccination was administered in subsequent encounters. Our study fills this research gap by looking at the post-resettlement period for a duration of 1 year. In our cohort, $8 \%$ of MMReligible subjects did not receive any doses of MMR vaccine within 1 year of resettlement, while $21 \%$ had received only one of the two-dose MMR vaccine series. This represents missed opportunities for the prevention of disease transmission, particularly in an era of frequent measles and mumps outbreaks.

Refugees in the U.S. frequently resettle from countries that lack nationwide hepatitis B vaccine programs, even 
though global hepatitis B vaccination coverage is improving [3]. Thirty percent of our cohort had baseline immunity against hepatitis $B$, which is comparable to a prior multi-center study of refugees [6]. We found that among those eligible for vaccination, only 59\% completed the three-dose hepatitis B vaccine series within 1 year of arrival. This compares favorably to the general U.S. adult population which reports $25 \%$ vaccine coverage for hepatitis B [19]. However, this value is still too low given that individuals from hepatitis B-endemic countries remain at risk of incident infection even after resettlement in non-endemic countries [20].

Ten percent of subjects in this cohort were nonimmune to varicella at the time of resettlement, which is consistent with previously published observations [7]. Varicella seroprevalence varies by age in different regions in the world; other studies have noted high varicella susceptibility in persons originating from tropical climates [21]. Varicella vaccination is not routinely available in many adult clinics (including ours at the time of this study) and therefore can be more challenging to provide for eligible adult patients. However, vaccination should be a priority since complications of varicella are more likely when primary infection occurs in adulthood [22].

Our study also evaluated the HPV vaccine series in eligible subjects. We found that among both men and women in our study cohort below the age of 26 years, only $15 \%$ had initiated the HPV vaccine series within 1 year of resettlement. Prior studies have noted marked disparities in HPV vaccination and cervical cancer screening among foreign-born persons in North America $[23,24]$. A study of female Vietnamese-Americans found comparable rates of HPV vaccination and specifically noted an increased odds of vaccination among those who correctly recognized that HPV infection was not curable with medications [25]. This suggests room for improved counseling and education regarding the nature of HPV infection as a means to increase vaccination rates among foreign-born persons.

An important finding of this study was that only $70 \%$ of the cohort completed HIV screening, whereas 99\% completed HCV screening. These data suggest a persistent stigma regarding HIV among refugee patients or a lack of perceived risk, despite an increased prevalence of risk factors for HIV and HCV infection among refugees, including exploitation during the migration process, exposure to sexual violence, and unregulated healthcare procedures [11]. HIV prevalence was $3 \%$ among those who underwent screening, which is comparable to a prior study of refugees resettling in Washington D.C. and higher than the general U.S. population [4]. Since 2010, refugees being resettled in the U.S. have not been required to undergo pre-departure HIV testing; HIV testing and counseling are therefore a crucial intervention in the refugee health assessment after arrival [11]. Our study reinforces the need to screen all refugees for both $\mathrm{HIV}$ and $\mathrm{HCV}$ in the current era of safe and effective therapies for both diseases to reduce the risk of long-term complications and transmission.

In a univariable analysis of predictors of vaccine completion among the vaccine-eligible, older age was associated with a lower odds of completing vaccination, particularly for those subjects greater than 50 years old. This may be related to decreased health literacy among older refugees or competing health issues for patients with more chronic conditions during follow-up visits. Subjects who were male and English speakers had greater odds of completing vaccination. This may be related to disparities in health literacy or challenges in navigating the healthcare system among refugees who are female and/ or non-English speakers [26, 27]. We do not believe that access to care or health insurance was a key determinant of these differences since all refugees in this cohort had insurance for the duration of this study and were seen in the same primary care network for other health needs.

These results should be interpreted within the limitations of study design. The seroprevalence estimates in this study may not reflect refugees who arrived in the U.S. after 2014, given the expansion of the Overseas Vaccination Program for U.S.-bound refugees and federal changes to refugee policies [10]. These data are from a single region in the U.S., serving refugees primarily from Iraq, Afghanistan, and East Africa. As compared to the rest of the state of Connecticut, and the remainder of the U.S., our study population under-sampled refugees originating from Southeast Asia, South Asia, Central/ South America, and Central Africa [28]. The sample size of this study population limited the precision of the point estimates and precluded a multivariable analysis. Therefore, the associations we found with vaccine completion may be subject to confounding. Although we could not capture vaccine administration in other healthcare settings, this was likely a rare occurrence because patients returned to the same primary care network for the rest of their healthcare needs. Further studies are needed to examine the reasons for incomplete vaccination and to develop approaches to improve vaccination among adult refugees. Reasons for incomplete vaccination in refugees, and effective approaches to improve vaccine completion, may be relevant to the general U.S. population more broadly [19].

\section{Conclusions}

In conclusion, almost all refugees eligible for vaccination with MMR, hepatitis A, and/ or hepatitis B initiated the recommended vaccination(s), but only $50 \%$ completed immunization within 1 year of their resettlement. 
Among those who completed HIV and HCV screening, $3 \%$ of refugees were newly diagnosed with HIV and $1 \%$ with chronic HCV. Refugee health providers must emphasize vaccinations and screening for chronic, treatable infections for their patients.

\section{Abbreviations}

MMR: Measles, mumps, and rubella; CDC: Centers for Disease Control and Prevention; HCV: Hepatitis C virus; IgG: Immunoglobulin G; Tdap: Tetanus, diphtheria, acellular pertussis; HPV: Human papillomavirus

\section{Acknowledgements}

Not applicable.

\section{Authors' contributions}

AMM: Conceptualization, Methodology, Formal Analysis, Investigation, Data Curation, Writing - Original Draft, Writing - Review and Editing. BB: Formal Analysis, Writing - Review and Editing. KSI: Formal Analysis, Writing - Review and Editing. EPH: Formal Analysis, Writing - Review and Editing. AA: Conceptualization, Methodology, Formal Analysis, Writing - Review and Editing, Supervision, Project Administration. The author(s) read and approved the final manuscript.

\section{Authors' information}

AMM and AA are members of the North American Society for Refugee Health Providers. AA is the Director of the Yale Refugee Clinic.

\section{Funding}

This work was supported by National Institutes of Health [Grant Number T32Al007433 to AMM; K01HL123349 to EPH]. Its contents are solely the responsibility of the authors and do not necessarily represent the official views of the National Institutes of Health.

\section{Availability of data and materials}

The datasets used and/or analysed during the current study are available from the corresponding author on reasonable request.

\section{Declarations}

\section{Ethics approval and consent to participate}

This study complied with national and international standards of ethics in research involving human subjects. This study was approved by the institutional review boards of Yale University School of Medicine and Massachusetts General Hospital and informed consent was waived by the same IRB for this retrospective study.

\section{Consent for publication}

Not applicable.

\section{Competing interests}

The authors declare no relevant conflicts of interest.

\section{Author details}

Medical Practice Evaluation Center, Massachusetts General Hospital, 16th Floor, 100 Cambridge Street, Boston, MA 02114, USA. ²Division of Infectious Diseases, Massachusetts General Hospital, Boston, MA, USA. ${ }^{3}$ Harvard Medical School, Boston, MA, USA. ${ }^{4}$ Department of Internal Medicine, Yale University School of Medicine, New Haven, CT, USA. ${ }^{5}$ Division of Infectious Diseases, Veterans Affairs Greater Los Angeles Healthcare System, Los Angeles, CA, USA. ${ }^{6}$ Division of Infectious Diseases, University of California Los Angeles, Los Angeles, CA, USA. ${ }^{7}$ Department of Psychiatry, Yale University School of Medicine, New Haven, CT, USA.

Received: 4 February 2021 Accepted: 30 April 2021

Published online: 16 June 2021

\section{References}

1. Hall V, Banerjee E, Kenyon C, Strain A, Griffith J, Como-Sabetti K, et al. Measles outbreak - Minnesota April-may 2017. MMWR. 2017;66(27):713-7. https://doi.org/10.15585/mmwr.mm6627a1.
2. Lam E, McCarthy A, Brennan M. Vaccine-preventable diseases in humanitarian emergencies among refugee and internally-displaced populations. Hum Vaccines Immunother. 2015;11(11):2627-36. https://doi. org/10.1080/21645515.2015.1096457.

3. U.S. Department of Health and Human Services, Centers for Disease Control and Prevention, National Center for Emerging and Zoonotic Infectious Diseases, Division of Global Migration and Quarantine. Guidance for evaluating and updating immunizations during the domestic medical examination for newly arrived refugees. 2021

4. Chai SJ, Davies-Cole J, Cookson ST. Infectious disease burden and vaccination needs among asylees versus refugees, District of Columbia. Clin Infect Dis. 2013;56(5):652-8. https://doi.org/10.1093/cid/cis927.

5. Lee $D$, Weinberg $M$, Benoit S. Evaluation of measles-mumps-rubella vaccination among newly arrived refugees. Am J Public Health. 2017;107(5): 684-6. https://doi.org/10.2105/AJPH.2017.303698.

6. Mitruka K, Pezzi C, Baack B, Burke H, Cochran J, Matheson J, et al. Evaluation of hepatitis B virus screening, vaccination, and linkage to care among newly arrived refugees in four states, 2009-2011. J Immigr Minor Health. 2019; 21(1):39-46. https://doi.org/10.1007/s10903-018-0705-x.

7. Greenaway C, Boivin JF, Cnossen S, Rossi C, Tapiero B, Schwartzman K, et al. Risk factors for susceptibility to varicella in newly arrived adult migrants in Canada. Epidemiol Infect. 2014;142(8):1695-707. https://doi.org/10.1017/ S0950268813002768.

8. Scott KC, Taylor EM, Mamo B, Herr ND, Cronkright PJ, Yun K, et al. Hepatitis $B$ screening and prevalence among resettled refugees - United States, 2006-2011. MMWR Morb Mortal Wkly Rep. 2015:64:4.

9. Terasaki G, Desai A, McKinney CM, Haider MZ. Seroprevalence of hepatitis B infection among immigrants in a primary care clinic: a case for granular ethnicity and language data collection. J Immigr Minor Health. 2017;19(4): 987-90. https://doi.org/10.1007/s10903-016-0543-7.

10. Mitchell T, Dalal W, Klosovsky A, Yen C, Phares C, Burkhardt M, et al. An immunization program for US-bound refugees: development, challenges, and opportunities 2012-present. Vaccine. 2021;39(1):68-77. https://doi.org/1 0.1016/j.vaccine.2020.10.047.

11. Winston SE, Beckwith CG. The impact of removing the immigration ban on HIV-infected persons. AIDS Patient Care STDs. 2011;25(12):709-11. https:// doi.org/10.1089/apc.2011.0121.

12. U.S. Department of Health and Human Services, Centers for Disease Control and Prevention, National Center for Emerging and Zoonotic Infectious Diseases, Division of Global Migration and Quarantine. Screening for HIV infection during the refugee domestic medical examination 2012.

13. Morrison TB, Wieland ML, Cha SS, Rahman AS, Chaudhry R. Disparities in preventive health services among Somali immigrants and refugees. J Immigr Minor Health. 2012;14(6):968-74. https://doi.org/10.1007/s10903-0129632-4.

14. Waldorf B, Gill C, Crosby SS. Assessing adherence to accepted national guidelines for immigrant and refugee screening and vaccines in an urban primary care practice: a retrospective chart review. J Immigr Minor Health. 2014;16(5):839-45. https://doi.org/10.1007/s10903-013-9808-6.

15. Centers for Disease Control and Prevention (CDC). Recommendations on the use of quadrivalent human papillomavirus vaccine in males -- Advisory Committee on Immunization Practices (ACIP), 2011. CDC MMWR. 2011;60: 1705-8. https://doi.org/10.1111/j.1600-6143.2012.04024.x

16. Markowitz LE, Dunne EF, Saraiya M, Chesson HW, Curtis CR, Gee J, et al. Human Papillomavirus vaccination recommendations of the Advisory Committee on Immunization Practices (ACIP). MMWR Morb Mortal Wkly Rep. 2014;63:1-30.

17. HHS-Office of Refugee Resettlement. Refugee Health Insurance. Off Refug Resettl ACF. 2019; https://www.acf.hhs.gov/orr/health (Accessed 14 Mar 2019).

18. Lee D, Philen R, Wang Z, McSpadden P, Posey DL, Ortega LS, et al. Disease surveillance among newly arriving refugees and immigrants--Electronic Disease Notification System, United States, 2009. Morb Mortal Wkly Rep Surveill Summ. 2013;62:1-20.

19. Centers for Disease Control and Prevention. Vaccination coverage among adults in the United States, National Health Interview Survey, 20172017

20. Whelan J, Sonder G, Heuker J, van den Hoek A. Incidence of acute hepatitis $B$ in different ethnic groups in a low-endemic country, 1992-2009: increased risk in second generation migrants. Vaccine. 2012;30(38):5651-5. https://doi.org/10.1016/j.vaccine.2012.06.080. 
21. Cadieux G, Redditt V, Graziano D, Rashid M. Risk factors for varicella susceptibility among refugees to Toronto, Canada. J Immigr Minor Health. 2017;19(1):6-14. https://doi.org/10.1007/s10903-015-0313-y.

22. Danovaro-Holliday MC, Gordon ER, Jumaan AO, Woernle C, Judy RH, Schmid DS, et al. High rate of varicella complications among Mexican-born adults in Alabama. Clin Infect Dis. 2004;39(11):1633-9. https://doi.org/10.1 086/425613.

23. Lofters A, Glazier RH, Agha MM, Creatore MI, Moineddin R. Inadequacy of cervical cancer screening among urban recent immigrants: a populationbased study of physician and laboratory claims in Toronto, Canada. Prev Med. 2007;44(6):536-42. https://doi.org/10.1016/j.ypmed.2007.02.019.

24. McDonald JT, Kennedy S. Cervical cancer screening by immigrant and minority women in Canada. J Immigr Minor Health. 2007;9(4):323-34. https://doi.org/10.1007/s10903-007-9046-x.

25. Yi JK, Anderson KO, Le Y-C, Escobar-Chaves SL, Reyes-Gibby CC. English proficiency, knowledge, and receipt of HPV vaccine in Vietnamese-American women. J Community Health. 2013;38(5):805-11. https://doi.org/10.1007/s1 0900-013-9680-2.

26. Mirza M, Luna R, Mathews B, Hasnain R, Hebert E, Niebauer A, et al. Barriers to healthcare access among refugees with disabilities and chronic health conditions resettled in the US Midwest. J Immigr Minor Health. 2014;16(4): 733-42. https://doi.org/10.1007/s10903-013-9906-5.

27. Gele AA, Pettersen $K S$, Torheim LE, Kumar B. Health literacy: the missing link in improving the health of Somali immigrant women in Oslo. BMC Public Health. 2016;16(1):1134. https://doi.org/10.1186/s12889-016-3790-6.

28. Refugee Processing Center, U.S. Department of State Bureau of Population Refugees, and Migration. Refugee Processing Center: admissions and arrivals. Refug Process Cent. 2019; Available from: http://www.wrapsnet. org/admissions-and-arrivals. Accessed 4 April 2021.

\section{Publisher's Note}

Springer Nature remains neutral with regard to jurisdictional claims in published maps and institutional affiliations.

Ready to submit your research? Choose BMC and benefit from:

- fast, convenient online submission

- thorough peer review by experienced researchers in your field

- rapid publication on acceptance

- support for research data, including large and complex data types

- gold Open Access which fosters wider collaboration and increased citations

- maximum visibility for your research: over $100 \mathrm{M}$ website views per year

At $\mathrm{BMC}$, research is always in progress.

Learn more biomedcentral.com/submissions 